\title{
Metatarsophalangeal Joint 5
}

National Cancer Institute

\section{Source}

National Cancer Institute. Metatarsophalangeal/oint 5. NCI Thesaurus. Code C102325.

A condyloid synovial joint within the fifth digit of the foot connecting metatarsal with the proximal phalanx. 